\title{
Essential hypertension in adult Nigerians in a primary care clinic: A cross sectional study of the prevalence and associated family socio-biological factors in Eastern Nigeria
}

\author{
Gabriel Uche Pascal Iloh ${ }^{1, *}$, Agwu Nkwa Amadi ${ }^{2}$ \\ ${ }^{1}$ Departments of Family Medicine, Federal Medical Centre, Umuahia, Abia state, Nigeria and Department of Public Health Technology, \\ Federal University of Technology, Owerri, Imo State, Nigeria \\ ${ }^{2}$ Department of Public Health Technology, Federal University of Technology, Owerri, Imo State, Nigeria
}

\section{Email address:}

ilohgup2009@yahoo.com (G. U. P. Iloh)

\section{To cite this article:}

Gabriel Uche Pascal Iloh, Agwu Nkwa Amadi. Essential Hypertension in Adult Nigerians in a Primary Care Clinic: A Cross Sectional Study of the Prevalence and Associated Family Socio-Biological Factors in Eastern Nigeria. European Journal of Preventive Medicine.

Vol. 2, No. 6, 2014, pp. 81-89. doi: 10.11648/j.ejpm.20140206.11

\begin{abstract}
Background: The prevalence of hypertension in primary care setting is showing an upward trend. However, the occurrence of hypertension is a reflection of not only family predisposition but interaction and clustering of socio-biological and behavioural factors. Aim: This was a cross sectional study of prevalence of essential hypertension and associated family socio-biological factors among adult Nigerians in a primary care clinic in Eastern Nigeria. Materials and Methods: A crosssectional study was carried out in May 2011 at a primary care clinic in South Eastern Nigeria. Hypertension was defined using JNC VII criterion. Data on family socio-biological variables were obtained using pretested, structured and intervieweradministered questionnaire. Results: The prevalence of hypertension was $12.3 \%$ and $61.7 \%$ of the hypertensive patients had their diagnosis made in the hospital. There were eighty-one (41.3\%) males and one hundred and fifteen(58.7\%) females with sex ratio of 1: 1.4. The age ranges from 18-82 years for males with mean age of 58 \pm 12.0 years whilst for females the age ranges from 18-84 years with mean age of $63 \pm 14.2$ years. Family biosocial factors significantly associated with hypertension was family size more than four $(\mathrm{P}=.045)$ and family history of hypertension $(\mathrm{P}=.024)$. The most significant family predictor variable was family history of hypertension $(\mathrm{OR}=3.49 \mathrm{P}=.026)$. The patient with family history of hypertension was three and half times more likely to be hypertensive than those without family history of hypertension. Conclusion: Hypertension occurs in adult Nigerians in the primary care and is associated with family size more than four and family history of hypertension. History of hypertension in the family during clinical encounter should stimulate the need for family oriented primary care and prevention.
\end{abstract}

Keywords: Adult Nigerians, Family Socio-Biological Factors, Hypertension, Prevalence, Primary Care

\section{Introduction}

Hypertension is a clinical and family health problem[1-3] and is the principal cardiovascular disease worldwide. $[4,5]$ It is defined currently as systolic and/or diastolic blood pressures $\geq 140 / 90 \mathrm{mmHg}$ in tandem with The Seventh Report of the Joint National Committee on prevention, detection, evaluation and treatment of high blood pressure in adults aged 18 years and older.[6] In recent years there has been increasing concern about the burden of noncommunicable diseases especially cardiovascular diseases and particularly hypertension in sub-Saharan African countries.[7,8] In Nigerian Africa, hypertension is the most common non-communicable and cardiovascular disease [9] and this places a significant burden on the families and nation's limited health facilities and constitutes the most important cause of morbidity and mortality from cardiovascular diseases in Nigerian families.[1,2,9]

Although the burden of hypertension is declining in highincome countries, they are increasing in virtually every other region of the developing nations. $[4,5,10,11]$ The consequences of this preventable epidemic of hypertension 
will be substantial on the individual and family dynamics resulting in individual and family suffering, stress, distress and dysfunction.[1,2] The prevalence of hypertension in populations has been reported to differ geographically [10] since it may be influenced by family socio-biological and other diverse factors.[1,2,11] Globally, about one billion people have hypertension, of these two thirds are in developing countries and in 2025; an estimated 1.56 billion adults will be living with hypertension. $[4,12]$ The trend in the prevalence of hypertension has been reported in United States of America[13] and in other parts of the world such as Brazil[3] and China.[14] In African continent, the prevalence of $16.2 \%$ was reported with estimated number of hypertensives of 75 million and a projected 125.5 million in 2025.[8] The burden of hypertension in Africa has been reported in Ghana, $[8,15]$ and in other parts of Africa like Ethiopia.[8] In Nigerian Africa, the estimated prevalence by World Health Organization was 42.8\%.[4] The prevalence range of $8 \%-46 \%$ was reported in a systematic review of prevalence of hypertension in adult Nigerians,[9] 22.5\% $31.0 \%$ was reported in Abia state non-communicable disease survey,[16] $26.4 \%$ was reported among patients with family history of cardiovascular diseases in Umuahia, Abia state[1] and $42.7 \%$, were reported among obese adult in primary care clinic in South-east Nigeria,[17] 18.4\%, was reported in obese adult patients in semi-urban hospital in Eastern Nigeria ,[18] and $16.3 \%$ was reported in adult obese Nigerians in a rural hospital in Eastern Nigeria[19] and $44.6 \%$ was reported among abdominally obese patients in Southeast, Nigeria.[20] Of great concern in Nigeria is the poor awareness of blood pressure status among the populace.[21] In addition to the poor awareness of blood pressure status there is also poor blood pressure control among hypertensive Nigerians.[22-24] Hypertension is the most common cause of adult emergences from cardiovascular disease in rural Nigeria [25] and was responsible for $25.3 \%$ of medical ward admissions in a teaching hospital in Kano, Northern Nigeria [26] and $45 \%$ of hypertension related medical admissions in Enugu, South-eastern Nigeria.[27] Hypertension has been reported to cause damage to target organs of the body like brain, heart and kidney of Nigerian patients and accounted for a large proportion of unnecessary deaths in Nigerian hospitals.[27-29]

In Nigeria, hypertension causes acute and chronic diseases and illnesses that impact on the quality of family life of affected individuals and place great burden on the individuals and families.[1,2] Of great concern in the study area is that there is myth that death whether sudden or protracted from stroke or heart attack is most times attributed to spells on the family. [1,2,27,30] Although clinicians in Nigeria are aware of the significance of hypertension in the family of individuals and its associated health consequences but they have not made it a routine to screen for family related determinants of hypertension among adult Nigerian patients in primary care settings. The early recognition of the irrevocable and revocable risk factors that predisposes to the occurrence of hypertension in the family is essential in the control of the hypertension in the family through family oriented primary care approach. [1,31-35] Surprisingly in Nigeria the family determinants of hypertension assume a relatively low priority and no data exists on their evaluation in primary care settings. Since hypertension is called the 'silent killer' because it often has no warning symptoms or signs, and many family members do not realize they have hypertension.[30] The most effective primary care intervention is screening for family socio-biological determinants during clinical encounter. Screening for family factors that predispose to hypertension is anticipated to provoke inquiry by clinicians on the implications of family biosocial factors among adult Nigerians with hypertension. Identifying significant family socio-biological risk factors for hypertension therefore avails great opportunity for early health promotion, lifestyle modifications as well as screening for other cardio-metabolic risk factors. It is against this background that the authors were motivated to study the prevalence of hypertension and its family socio-biological factors in adult Nigerians in a primary care clinic in Eastern Nigeria.

\section{Materials and Methods}

\subsection{Ethical Issues}

Ethical certificate was obtained from the Health Research and Ethics Committee of the hospital. Informed consent was also obtained from patients included in the study.

\subsection{Design}

This was a primary care clinic-based cross sectional study carried out in May 2011 at the department of Family Medicine of Federal Medical Centre, Umuahia, a tertiary hospital in Umuahia, Abia state, South-Eastern, Nigeria. A total of 1600 adult patients were screened for hypertension using The Seventh Report of the Joint National Committee on prevention, detection, evaluation and treatment of high blood pressure in adults aged 18 years and older and 196 patients who had systolic and/or diastolic blood pressures of $\geq 140 / 90 \mathrm{mmHg}$ or documented use of antihypertensive medications in a previously diagnosed person with hypertension [1] were age and sex matched with 196 nonhypertensive patients.

\subsection{Setting}

Umuahia is the capital of Abia state, South-East Nigeria. Abia state is endowed with abundant mineral and agricultural resources with supply of professional, skilled, semi-skilled and unskilled manpower. Economic and social activities are low compared to industrial and commercial cities such as Onitsha, Port Harcourt and Lagos in Nigeria. Until recently, the capital city and its environ have witnessed an upsurge in the number of banks, hotels, schools, markets, industries, junk food restaurants in addition to the changing dietary and social lifestyles.

Federal Medical Centre, Umuahia is located in the 
metropolitan city of Umuahia. It is a tertiary hospital established with the tripartite mandate of service delivery, training and research and serves as a referral Centre for primary and secondary public health institutions as well as missionary and private hospitals in Abia state and neighbouring states of Imo, Ebonyi, Rivers and Akwa Ibom states of Nigeria.

The department of Family Medicine serves as a primary care clinic within the tertiary hospital setting of the Federal Medical Centre. All adult patients excluding those who need emergency health care services, paediatric patients and antenatal women are first seen at the department of Family Medicine where diagnoses are made. Patients who need primary care are managed and followed up in the clinic while those who need other specialists care are referred to the respective core specialist clinics for further management. The clinic is run by Consultant Family Physicians and postgraduate resident doctors in Family Medicine.

\subsection{Study Population}

One thousand and six hundred adult Nigerian patients were seen during the study period. Out of this, one hundred and ninety six patients who had essential hypertension and one hundred and ninety six normotensives patients who met the inclusion criteria were studied for family socio-biological factors. The normotensive patients were selected from primary care clinic of the hospital and were matched for age and sex with the hypertensive patients. The matching for the age was based on age group frequency matching. The hypertensive and normotensive patients were studied simultaneously during the study period.

\subsection{Inclusion and Exclusion Criteria}

The inclusion criteria were adult Nigerian patients aged $\geq$ 18 years and who gave consent for the study. The exclusion criteria included critically ill patients, pregnant hypertensives and patients with established cause of hypertension.

\subsection{Sample Size Determination}

Sample size estimation was determined using the formula [36] $\mathrm{N}=\mathrm{Z}^{2} \mathrm{pq} / \mathrm{d}^{2}$ where $\mathrm{N}=$ Minimum sample size, $\mathrm{Z}=$ Standard normal deviation usually set at 1.96 which corresponds to $95 \%$ confidence interval, $\mathrm{P}=$ Proportion of the population estimated to have a particular characteristic. Proportion was taken from previous hospital-based study in Katsina, Northern Nigeria [37] $=25.7 \%(0.26) . \quad \mathrm{q}=1.0-\mathrm{p}=1.0$ $0.26=0.74, \mathrm{~d}=$ degree of accuracy set at 0.05 . Hence $\mathrm{N}=$ $(1.96)^{2} \times 0.26 \times 0.74 /(0.05)^{2}$. Therefore, $\mathrm{N}=296$. This gave a sample size estimate of 296. The calculated minimum sample size was 296 . However, to improve the precision of the study and compensate for non-response, the estimated sample size $=\mathrm{Ns}$ was determined considering an anticipated response rate of $90 \%(0.9)$. The estimated sample size (Ns) was determined by dividing the original calculated sample size $(\mathrm{N})$ by the anticipated response rate as follows, [36] $\mathrm{Ns}=\mathrm{N} / 0.9$, where $\mathrm{N}=$ Minimum calculated sample size, Ns=Selected sample size, anticipated response rate $=0.9$. Thus, the estimated sample size $=296 / 0.9=329$. However, a sample size of 392 patients (196 hypertension patients and 196 nonhypertensive patients) was used based the duration of the study.

\subsection{Sampling Techniques}

The sample selection was done consecutively using every adult patient who registered to see the clinicians on each consulting day during the study period and who met the inclusion criteria. This sampling method was judgementally chosen by the authors based on the fact that the researchers believed that those selected were likely to be representative of the study population.

\subsection{Diagnostic Procedure for Hypertension}

The blood pressure was measured using auscultatory method with standard mercury in glass Accuson sphygmomanometer.[2] Prior to the measurement, the patient was seated and rested for 5 minutes in sitting position on a chair that supported the back comfortably. The left arm muscles were relaxed and the forearm was supported with the cubital fossa at the heart level. A cuff of suitable size was applied evenly to the exposed arm. The cuff was rapidly inflated until the manometer reading was about $30 \mathrm{mmHg}$ above the level at which the pulse disappeared and then slowly deflected. During this time, the Korotkoff sounds were monitored using a Litman stethoscope placed over the brachial artery. The systolic blood pressure was noted at the pressure at which the first heart sounds were heard (Korotkoff phase I). The diastolic blood pressure was taken as the pressure at the point when the heart sounds disappeared (Korotkoff phase V). The blood pressure was also measured in the right arm as described for the left arm in order to rule out significant inter-arm blood pressure difference and the arm that gave the higher reading was subsequently used.

\subsection{Diagnostic Criterion for Hypertension}

Hypertension was defined as the systolic and/or diastolic blood pressures of $\geq 140 / 90 \mathrm{mmHg}$ or documented use of antihypertensive medications in a previously diagnosed person with hypertension. [1]

\subsection{Methods}

The research tool was adapted from the generic WHOSTEPS instrument approach to surveillance of chronic noncommunicable diseases risk factors[38] and was modified to suit Nigeria environment through robust review of relevant literature.[1,2,33,34] The family socio-biological factors studied were type of marital union, type of household, family size and family histories of cardio-metabolic risk factors such as hypertension, diabetes mellitus, obesity, stroke and sudden death; family dietary salt, fruits and vegetables consumptions during meal times and type of oils use in household meal preparations. 
The family history of hypertension, obesity, diabetes mellitus, stroke and sudden death was coded as yes or no for the presence or absence of hypertension, obesity, diabetes mellitus, stroke and sudden death in any of the first, second or third degree generation family members respectively.[1,2]

The family dietary factors of fruits and vegetables consumption were evaluated by asking how many days in the previous 7 days do the family eat fruits and vegetables.[1,2] The dietary responses were graded into: never $(0$ serving/week), rarely ( $<3$ servings/week) and oftentimes $(\geq 3$ servings/week). Those who have $\geq 3$ servings/week have adequate dietary fruits intake while those who had 0 serving/week and <3 servings/week have inadequate dietary fruits and vegetables consumption respectively. The question on dietary salt was evaluated by inquiring whether the family add raw table salt in addition to the one used to cook meals during meal times. The dietary salt consumption responses were coded yes or no. The question on family dietary use of oils was got by inquiring in the previous 7 days the type of oils used in household meal preparations. The information on family dietary measurements was based on previous 7 days dietary recall method. This method was expected to give required information on family dietary assessment based on the feasibility in Nigerian socio-family context. [1,2]

\subsection{Operational Definitions}

Socio-biological risk factors of hypertension refer to antecedent condition(s) whose presence is(are) positively associated with an increased probability that hypertension will develop later.[1] Family history of primary cardiometabolic diseases such as hypertension, diabetes mellitus, obesity and adverse cardiovascular events(stroke and sudden death) refers to previous information on the occurrence of hypertension, diabetes mellitus, obesity and adverse cardiovascular events in any of the first, second or third degree generation family members who were dead or alive made by a health professional.

The socio-biological risk factors studied included the traditional non-modifiable factors of family history of obesity, hypertension, diabetes mellitus and adverse cardiovascular events; modifiable dietary factors of consumption of dietary salt, fruits, vegetables and type of household cooking oils. Family refers to two parents and their child(ren) or single parent family made of either parent or their child (ren). Household family in Nigerian family demographic geography refers to a number of persons eating from the same pot. Primary care refers to the care provided by physicians specifically trained for comprehensive first contact and continuing care for undifferentiated patients including early detection, management of the patient, health promotion and maintenance. Proband or consultand refers to the index patient who presented in the clinic for family case study and investigations.

\subsection{Statistics}

The results generated were analyzed using software
Statistical Package for Social Sciences (SPSS) version 13.0, Microsoft Coperation Inc. Chicago, IL, USA. Data analysis was based on univariate frequency table distribution and bivariate cross tabulations to identify important relationships between variables using Chi-square statistics. Odds ratio(OR) and predictor variable analysis using simple logistic regression at $95 \%$ confidence limit was restricted to the variable measures that were statistically significant at bivariate analysis. A p-value of $<0.05$ was considered statistically significant.

\section{Results}

Out of the one thousand six hundred adult patients screened for hypertension, one hundred and ninety six were hypertensive giving a prevalence of $12.3 \%$. [Table 1]

The age of the hypertensive patients ranged from 18 years to 82 years for males with mean age of $58 \pm 12.0$ years whilst the age range for females was 18 years to 84 years with mean age of $63 \pm 14.2$ years. There were eighty one $(41.3 \%)$ males and one hundred and fifteen $(58.7 \%)$ females with male to female ratio of 1:1.4. Other socio-demographic profiles of the study population are shown in Table 2.

On bivariate analysis of family basic demographic profiles as related to hypertension showed that family size more than four $\left(\mathrm{x}^{2}=8.66, \mathrm{P}=0.045\right)$ was statistically significant while other basic family demographic variables were not statistically significant. [Table 3]

Table 1. Prevalence of hypertension among the study population

\begin{tabular}{ll}
\hline Parameter & Number $(\%)$ \\
\hline Hypertension & \\
Yes & $196(12.3)$ \\
No & $1404(87.7)$ \\
Total & $1600(100.0)$ \\
\hline
\end{tabular}

Table 2. Age and sex distribution of the hypertensive patients

\begin{tabular}{lll}
\hline Parameter & & \\
\hline \multirow{2}{*}{ Age(group)(years) } & Male & Female \\
& Number(\%) & Number(\%) \\
\hline $18-39$ & $19(23.5)$ & $27(23.5)$ \\
$\geq 40$ & $62(76.5)$ & $88(76.5)$ \\
Total & $81(100.0)$ & $115(100.0)$ \\
\hline
\end{tabular}

Table 3. Family demographic profiles as related to hypertension among the study population

\begin{tabular}{|c|c|c|c|c|}
\hline \multirow[b]{2}{*}{ Variables } & \multicolumn{2}{|c|}{ Hypertension } & \multirow[b]{2}{*}{$x^{2}$} & \multirow[b]{2}{*}{ P-value } \\
\hline & $\begin{array}{l}\text { Yes } \\
\text { Number }(\%)\end{array}$ & $\begin{array}{l}\text { No } \\
\text { Number }(\%)\end{array}$ & & \\
\hline \multicolumn{5}{|l|}{ Type of marital union } \\
\hline Monogamous & $173(88.3)$ & $182(92.9)$ & & \\
\hline Polygamous & $23(11.7)$ & $14(7.1)$ & 4.19 & $0.399 * *$ \\
\hline \multicolumn{5}{|l|}{ Family size } \\
\hline $1-4$ & $66(33.7)$ & $49(25.0)$ & & \\
\hline$>4$ & $130(66.3)$ & $147(75.0)$ & 8.66 & $0.045^{*}$ \\
\hline \multicolumn{5}{|l|}{ Type of household } \\
\hline Nuclear household family & $180(91.8)$ & 187(95.4) & & \\
\hline Extended household family & $16(8.2)$ & $9(4.6)$ & 9.02 & $0.083 * *$ \\
\hline
\end{tabular}

Remark: *Significant, **Non-significant 
Table 4. Family history of cardio-metabolic risk factors as related to hypertension among the study population

\begin{tabular}{lllll}
\hline \multirow{2}{*}{ Variables } & \multicolumn{2}{l}{ Hypertension } & & \\
\cline { 2 - 3 } & $\begin{array}{l}\text { Yes } \\
\text { Number(\%) }\end{array}$ & $\begin{array}{l}\text { No } \\
\text { Number(\%) }\end{array}$ & P-value \\
\hline $\begin{array}{l}\text { Family history of } \\
\text { hypertension }\end{array}$ & & & & \\
Yes & $139(70.9)$ & $92(46.9)$ & & \\
No & $57(29.1)$ & $104(53.1)$ & 9.35 & $0.024^{*}$ \\
$\begin{array}{l}\text { Family history of } \\
\text { diabetes mellitus }\end{array}$ & & & & \\
Yes & $77(39.3)$ & $46(23.5)$ & & \\
No & $119(60.7)$ & $150(76.5)$ & 10.55 & $0.079^{* *}$ \\
$\begin{array}{l}\text { Family history of } \\
\text { cerebrovascular }\end{array}$ & & & & \\
accident(Stroke) & & & & \\
Yes & $28(14.3)$ & $12(6.1)$ & & \\
No & $168(85.7)$ & $184(93.9)$ & 8.01 & $0.094^{* *}$ \\
$\begin{array}{l}\text { Family history of } \\
\text { sudden death }\end{array}$ & & & & \\
Yes & $11(5.6)$ & $8(4.1)$ & & \\
No & $185(94.4)$ & $188(95.9)$ & 4.06 & $0.189^{* *}$ \\
\hline
\end{tabular}

Remark: *Significant, **Non-significant

Bivariate analysis of family history of cardio-metabolic risk factors as related to hypertension showed that family history of hypertension $\left(\mathrm{x}^{2}=9.35, \mathrm{P}=0.024\right)$ was statistically significant while other family history of cardio-metabolic risk factors were not statistically significant.[Table 4]

Bivariate analysis of family dietary factors as related to hypertension showed that none of the family dietary factors was statistically significant. [Table 5]

On simple logistic regression of the statistically significant variables family history of hypertension remained statistically significant. [Table 6] A significantly higher proportion of the hypertensive patients had family history of hypertension compared to the non hypertensive control. (OR=3.49., $\quad \mathrm{CI}=0.146-2.352, \quad \mathrm{P}$-value=0.026) $\quad$ The hypertensive patients were three and half times more likely to have family history of hypertension compared to the non hypertensive counterparts.

Table 5. Family dietary factors as related to hypertension among the study population

\begin{tabular}{|c|c|c|c|c|}
\hline \multirow[b]{2}{*}{ Variables } & \multicolumn{2}{|l|}{ Hypertension } & \multirow[b]{2}{*}{$\mathrm{x}^{2}$} & \multirow[b]{2}{*}{ P-value } \\
\hline & $\begin{array}{l}\text { Yes } \\
\text { Number(\%) }\end{array}$ & $\begin{array}{l}\text { No } \\
\text { Number(\%) }\end{array}$ & & \\
\hline \multicolumn{5}{|l|}{$\begin{array}{l}\text { Family dietary } \\
\text { fruits consumption }\end{array}$} \\
\hline Adequate & $36(18.4)$ & $28(14.3)$ & & \\
\hline Inadequate & $160(81.6)$ & $168(85.7)$ & 7.61 & $0.203 * *$ \\
\hline \multicolumn{5}{|l|}{$\begin{array}{l}\text { Family dietary } \\
\text { vegetables } \\
\text { consumption }\end{array}$} \\
\hline Adequate & $63(32.1)$ & $85(43.4)$ & & \\
\hline Inadequate & 133(67.9) & 111(56.6) & 4.12 & $0.096^{* *}$ \\
\hline \multicolumn{5}{|l|}{$\begin{array}{l}\text { Family dietary } \\
\text { oils/fats } \\
\text { consumption }\end{array}$} \\
\hline Saturated & 171(87.2) & 185(94.4) & & \\
\hline $\begin{array}{l}\text { Unsaturated } \\
\text { Family dietary raw } \\
\text { salt consumption }\end{array}$ & $25(12.8)$ & $11(5.6)$ & 6.36 & $0.088^{*}$ \\
\hline
\end{tabular}

\begin{tabular}{lllll}
\hline \multirow{2}{*}{ Variables } & \multicolumn{2}{l}{ Hypertension } & \multirow{2}{*}{$\mathbf{x}^{2}$} & P-value \\
\cline { 2 - 3 } & $\begin{array}{l}\text { Yes } \\
\text { Number(\%) }\end{array}$ & $\begin{array}{l}\text { No } \\
\text { Number(\%) }\end{array}$ & \\
\hline Yes & $10(5.1)$ & $32(16.3)$ & & \\
No & $186(94.9)$ & $164(83.7)$ & 9.94 & $0.560^{* *}$ \\
\hline
\end{tabular}

Remark: *Significant, **Non-significant

Table 6. Simple logistic regression analysis of significant family variables

\begin{tabular}{lccc}
\hline Variables & $\begin{array}{c}\text { Odds } \\
\text { ratio }\end{array}$ & $\begin{array}{l}\text { Confidence } \\
\text { interval (95\%) }\end{array}$ & P-value \\
\hline Family size & & & \\
$1-4$ & 1.0 & & \\
$>4$ & 1.87 & $0.500-1.799$ & $0.310^{* *}$ \\
Family history of hypertension & & & \\
No & 1.0 & & \\
Yes & 3.49 & $0.146-2.352$ & $0.026^{*}$ \\
\hline
\end{tabular}

Remark: *Significant, **Non-significant

\section{Discussion}

The prevalence of hypertension in this study was $12.3 \%$. This is within the $10-15 \%$ reported from Nigerian national survey in 1997; less than the prevalence of $14.0 \%-20.0 \%$ extrapolation from 1997 non-communicable diseases survey in Nigeria using blood pressure cut-off point of 140/90 $\mathrm{mmHg}$ and within the $8.0 \%-46.0 \%$ reported in a systematic review of prevalence of hypertension in adult Nigerian Africans. [9 However, the prevalence in this study is lower than the prevalence of $20.2 \%$ reported in Benin City, SouthSouth Nigeria,[39] 30.6\% reported in Ibadan, South-West Nigeria, [40] 25.7\% reported in Katsina, North-West Nigeria [37] and in other parts of the world such as Ghana where reported prevalence was $28.7 \%$,[15] Portugal with reported prevalence of $19.3 \%$,[41] 25.0\% reported in Brazil [3] and 27.2\% reported in Chinese population [14]. The reported variations in the prevalence of hypertension are attributed to the epidemiological profiles of the study population since the burden of hypertension has been described to differ geographically and is determined by socio-biological and environmental factors and changing lifestyles. The reported prevalence in this study could be a reflection of the clinic setting which is primary care. The implications of the finding of this study is a cause for concern especially in Nigerian environment where a significant proportion of the populace seek health care from alternative medical practitioners, patent medicine vendor and dealer outlets where regular and routine screening for hypertension is not practiced. Although hospital-based (opportunistic) screening for hypertension may not detect larger percentage of adult Nigerians with essential hypertension but family-based (targeted) screening can improve case detection rate for hypertension. The consequences of the emerging epidemic of hypertension in the study area will be substantial on individual and family resulting in increase in utilization of limited health care facilities in Nigeria amidst absence of universal health insurance coverage for the citizenry.[42,43] In the face of 
fewer health resources to control hypertension in the families,[22,33] it is pertinent to identify primary and family centred strategies that are inexpensive, culturally practicable and widely available. Although some individual members of the family may prefer prescription of pills to proscription of unhealthy lifestyle but there is growing evidence that lifestyle modification will provide greater benefits than any pill taking regimen.[33]

This study has shown that $61.7 \%$ of the patients were first diagnosed hypertensive at the study Centre which is a tertiary and referral hospital. The failure to diagnose hypertension in a health facility in Nigeria is a cause for concern considering the enormous negative impact of undiagnosed hypertension on the patients. Although hypertension is called a 'silent killer', it is surprising that $61.7 \%$ of the patients had the initial diagnosis of their hypertensive medical condition at the hospital rather than the peripheral primary and comprehensive health facilities. This finding is a reflection of the pattern of hospital attendance in the region and quality of care received at the peripheral primary and comprehensive health centres in the region where blood pressure is not routinely measured or measured with a faulty sphygmomanometer apparatus or inaptitude on the use of the blood pressure apparatus by attending primary and community health officers and nurses. The primary and comprehensive health centres in the environment are equipped with poorly-functional blood pressure measurement instrument, thus majority of the asymptomatic hypertensive patients are missed at presentation. If the asymptomatic hypertensive patients are diagnosed at the first point of contact with the health system it becomes easier to educate and counsel them on the management of their hypertensive condition including lifestyle modifications. This finding is therefore a clarion call on the need to develop functionally equipped primary and comprehensive level of care in the region. This would invariably help in early case detection of hypertension at the primary and comprehensive health care facilities and allow the tertiary hospitals in the area to concentrate on more challenging health problems and other statutory responsibilities of training and health research.

This study has shown that hypertension was significantly found in patients with family history of hypertension compared to those without the family history of hypertension. This could be a reflection of not only the genetic vulnerability but also other diverse factors favouring the aggregation of hypertension in the family.[44,45] Family history of hypertension should therefore prompt the need for assessment for hypertension at initial clinical encounter and evaluating them appropriately during subsequent visits. The earlier the primary prevention is started at the prepathogenesis phase, the more likely it is to be beneficial. Opportunistic and targeted evaluation for hypertension should therefore be part of the primary care imperative in resource-poor settings especially among patients with family history of hypertension.

This study has shown that large family size more than four is associated with hypertension. This could be attributed to the generalization that large family size is more likely to be characterized by relative high rate of stress, distress and poor family function and support especially in Nigerian environment where there is limited option for family wealth and social services.[42,46,47] The large family size background provides an unhealthy determinants of health which predispose to chronic stress and ill-health including occurrence of hypertensive disorder. Research has shown the role of stress and distress in the epidemiology of hypertension.[48,49] Stress have been shown to have pressor effects on the cardiovascular system causing increase sympathetic activity, metabolic derangements, trophic and structural changes, thrombotic and humoral changes which damage the target organs of the body such as the heart and brain.[49] The increased sympathetic activity is characterized by haemodynamic consequences of increase cardiac output, tachycardia, coronary vasoconstriction and proarrythmias. However, the haemodynamic changes associated with stress may not be sustained but wanes with time except in those with background essential hypertension where stress and distress are trigger factors. Hypertension is therefore the end result of neurohumoral derangement induced by stress. Although stress reaction is phylogenically essential for socio-environmental adaptation, not every person with family stress develop hypertension but their chances are higher especially if the coping mechanism is poor and particularly if the stress is chronic to induce protracted enhancement of humoral and neural processes among which sympathetic effects predominates resulting in many cardiovascular end points including hypertension. Appreciating the role of large family size-related stress in the occurrence of hypertension would sensitize primary care clinicians to see every encounter with patients who have large family size as an opportunity to evaluate for hypertension. The primary care physicians should be aware of this disposition in other to tailor management interventions to accommodate this health care determinant.

\section{Study Implications}

The family institution is the most basic social unit which influences the health status and behaviour of its members and addresses itself to the socio-medical needs and demands of the members. There is evidence that primary prevention of hypertension bestows great advantages and that hypertension control interventions are aimed at building human and institutional resources to prevent the burden of hypertension in the family. The Nigerian families constitute important human and social resources in which health promotion, risk reduction and health maintenance on prevention of hypertension should take place. Family biosocial variables have been shown to play a role in family health and diseases. The elucidation of family biosocial factors that influence hypertension will informed the need for family oriented intervention programs for hypertension in the study area. This study will therefore sensitize primary care clinicians in the study area to routinely screen for hypertension and evaluate for family predisposing factors during clinical 
consultations with adult Nigerians and will help to prevent missed opportunities for family oriented health promotion and health maintenance interventions.

\section{Study limitations}

The limitations imposed by the study are recognized by the researchers. First and foremost, information were collected from the consultand or proband and not from all the family members and so the findings may be subject to information bias. This also made it difficult to study other family variables such as family physical activity among others.

More so, the limitation imposed by the cross sectional study design is recognized. The cross sectional study design didn't allow elucidation of the direct effects of predictor family biosocial variables on hypertension and vice versa. The cross sectional design allows only establishment of an association between dependent and independent variables. Further longitudinal studies to explore the interactions as well as studies to unravel its clinical relevance in the study area are advocated.

\section{Strengths of the Study}

This study is the first study in the study area to highlight the association between hypertension and family sociobiological al variables. The sample size is larger than the minimum estimated sample size and the population 1600 patients screened for hypertension in a hospital based study is also relevant.

\section{Conclusion}

This study has shown that hypertension occurs in adult Nigerians in primary care and is associated with family size more than four and family history of hypertension. History of hypertension in the family and large family size during clinical encounter should stimulate the need for screening for hypertension in primary care in order to institute family oriented preventive interventions.

\section{Future Research Direction}

In the study area, further hospital-based and communitybased studies are recommended in order to further explore other family related hypertensive risk factors and its correlates. This will provide valuable clinical and community epidemiological data for collaborative purposes.

\section{References}

[1] Iloh GUP, Chuku A, Obiegbu NP, Ofoedu JN, Ikwudinma AO. Frequency of cardiovascular risk factors in adult Nigerians with family history of non-communicable cardiovascular disease in a primary care clinic of a tertiary hospital in a resource-constrained environment of Eastern Nigeria. American Journal of Health Research 2013; 1(1): 17-25.
[2] Iloh GUP, Amadi AN, Ikwudinma AO, Njoku PU. Prevalence and family biosocial predictors of abdominal obesity among adult Nigerian Africans in a resource constrained setting of a rural hospital in Eastern Nigeria. European Journal of Preventive Medicine 2013; 1: 70-78.

[3] Araujo J, Salerno H, Scala L. Prevalence and epidemiological profile of hypertension in the adult population of the family health program in Cuiba, Mato Grasso, Brazil. J Hypertens 2004;XXII(Suppl 1):S107.

[4] Mendis S, Puska P, Norrving B. Global Atlas on Cardiovascular Disease Prevention and Control World Health Organization in collaboration with the World Heart Federation and World Stroke Organization, Geneva 2011.

[5] Yach D, Hawkees C, Gouuld CL, Hofman KJ. The global burden of chronic diseases: overcoming the impediments to prevention and control. JAMA 2004;291: 2616-2622.

[6] Chobanian AV, Bakris GL, Black HR, Cushman WC, Green LA, Izzo JL et al. The seventh report of the Joint National Committee on Prevention, Detection, Evaluation and Treatment of high blood pressure: The JNC VII report. JAMA 2003; 289: 2560- 2572.

[7] Kadiri S. Tackling cardiovascular diseases in Africa. BMJ, West Africa edition 2005;8(4): 172-173.

[8] Twagirumukiza M, De Bacquer D, Kips JG, de Backer G, Stichele RV, Van Bortel LM. Current and projected prevalence of arterial hypertension in sub-Saharan Africa by sex, age and habitat: an estimate from population studies. J Hypertens 2011; 29: $1243-1252$.

[9] Ogah OS, Okpechi I, Chukwuonye II, Akinyemi JO, Onwubere BJC, Falase AO, Stewart S, Sliwa K. Blood pressure, prevalence of hypertension and hypertension related complications in Nigerian Africans: A review. World J Cardiol 2012; 4: 327-340.

[10] Kearney PM, Whelton M, Reynolds K, Muntner P, Whelton PK, He J. Global burden of hypertension. J Hypertens 2004; XXII(Suppl 1):S140.

[11] Olatunbosun ST, Kaufman JS, Cooper RS, Bella AF. Hypertension in a black population: Prevalence and biosocial determinants of high blood pressure in a group of urban Nigerians. J Hum Hypertens 2000; 14: 249-257.

[12] Kearney PM, Whelton M, Reynolds K, Muntner P, Whelton PK, He J. Global burden of hypertension: analysis of worldwide data. Lancet 2005; 365: 217-223.

[13] Wolf-Maier K, Cooper RS, Banegan JR. Hypertension prevalence and blood pressure levels in six European countries, Canada and the United States. JAMA 2003; 289:2363-2369.

[14] Gu D, Reynolds K, Wu X, Chen J, Duan X and Muntner P. Prevalence, awareness, treatment and control of hypertension in China. Hypertension 2002; 40:920-927.

[15] Amoah AGB. Hypertension in Ghana: a cross-sectional community prevalence study in Greater Accra. Ethn Dis 2003; 13: $310-315$.

[16] Ogah OS, Madukwe OO, Chukwuonye II, Onyeonoro UU, Ukaegbu AU, Akhimien MO et al. Prevalence and determinants of hypertension in Abia State Nigeria: results from the Abia State Non-Communicable Diseases and Cardiovascular Risk Factors Survey. Ethn Dis 2013; 23: 161-167. 
[17] Iloh GUP, Ikwudinma AO, Obiegbu NP. Obesity and Its Cardio-metabolic Co-morbidities Among Adult Nigerians in a Primary Care Clinic of a Tertiary Hospital in South-Eastern Nigeria. J Fam Med Primary Care 2013; 2: 20-26.

[18] Iloh GUP, Amadi AN, Nwankwo BO. Obesity in adult Nigerians: a study of its prevalence and common primary comorbidities in a semi-urban Mission General Hospital in South-Eastern Nigeria. Niger J Med 2010; 19: 459-466.

[19] Iloh GUP, Amadi AN, Nwankwo BO, Ugwu VC. Obesity in adult Nigerians: A study of its pattern and common primary co-morbidities in a rural Mission General Hospital in Imo state, south-eastern Nigeria. Niger J Clin Pract 2011; 14: 212218.

[20] Iloh GUP, Ikwudinma AO Abdominal obesity in adult Nigerian Africans: prevalence and co-occurrence with cardiometabolic risk factors in a resource poor setting of a rural hospital in Eastern Nigeria. American Journal of Health Research 2013; 1: 73-80.

[21] Omuemu VO, Okojie OH, Omuemu CE. Awareness of high blood pressure status, treatment and control in a rural community in Edo state. Nigerian Journal of Clinical Practice 2007; 10:208-212.

[22] Iloh GUP, Ofoedu JN, Njoku PU, Amadi AN, Godswill-Uko EU. Medication adherence and blood pressure control amongst adults with primary hypertension attending a tertiary hospital primary care clinic in Eastern Nigeria. African Journal of Primary Health Care \& Family Medicine 2013; 5: 446.

[23] Iloh GUP, Ofoedu JN, Njoku PU, Amadi AN. Blood pressure control among geriatric Nigerians with essential hypertension in a rural hospital in South-Eastern Nigeria. Port Harcourt Medical Journal 2013; 50-58.

[24] Akpa MR, Alasia DD, Emem-chioma PC. An appraisal of hospital based blood pressure control in Port Harcourt, Nigeria. Nigerian Health J. 2008;8:27-30.

[25] Iloh GUP, Amadi AN, Awa-Madu J. Common geriatric emergencies in a rural hospital in South-Eastern, Nigeria. Niger J Clin Pract 2012; 15: 333-337.

[26] Sani MU, Mohammed AZ, Bapp A, Borodo MM. A three year review of mortality patterns in the medical wards of Aminu Kano Teaching Hospital Kano, Nigeria. Niger Postgrad Med J 2007; 14: 347-351.

[27] Arodiwe EB, Ike SO, Nwokediuko SC. Case fatality among hypertension-related admissions in Enugu, Nigeria. Niger $\mathbf{J}$ Clin Pract 2009; 12: 153-156.

[28] Familoni OB, Alebiosu CO, Odusan A, Raimi A. Factors influencing target organ damage among hypertensive patients. Tropical Cardiology 2003; 29: 21-24.

[29] Ayodele OE, Alebiosu CO, Salako BL, Awoden OG, Adigun A. Target organ damage and associated clinical conditions among Nigerians with treated hypertension.Cardiovasc J South Afr 2005; 16: 89-93.

[30] Oke DA, Bandele EO. Misconception of hypertension. J Natl Med Assoc 2004; 96: 1221-1224.

[31] Yoon PW, Scheuner MT, Peterson-oehlke KL, Gwinn M, Faucett A, Khoury MJ. Can family history be used as a tool for public health and preventive medicine? Genet Med 2002;
4: 304-310.

[32] Rich EC, Burke W, Henton CJ, Haga S, Pinsky L, Short P, et al. Reconsidering the family history in primary care. J Gen Intern Med 2004; 19: 273-280.

[33] Iloh GUP, Amadi AN, Okafor GOC, Ikwudinma AO, Odu FU, Godswill-Uko EU. Adherence to lifestyle modifications among adult hypertensive Nigerians with essential hypertension in a primary care clinic of a tertiary hospital in resource-poor environment of Eastern Nigeria. British $\mathrm{J}$ of Med \& Medical Research 2014; 4: 3478-3490.

[34] Lim SS, Vos T, Flaxman AD. A comparative risk assessment of burden of disease and injury attributable to 67 risk factors and risk factor clusters in 21 regions, 1990-2010: a systematic analysis for the Global Burden of Disease Study. Lancet 2012; 380: 2224-2260.

[35] Uwanuruochi K, Ukpabi OJ, Onwuta CN, Onwubere BJ, Anisiuba BC, Michael FS. Cardiovascular risk factors in adult staff of Federal Medical Centre Umuahia: A comparison with other Nigerian studies. West Afr J Med 2013; 32: 243-247.

[36] Araoye MO. Sample size determination. Research Methodology with Statistics for Health and Social Sciences, Ilorin: Nathadex Publishers, 2004; p.115-121.

[37] Sani MU, Wahab KW, Yusuf BO, Gbadamosi M, Johnson OV, Gbadamosi A. Modifiable cardiovascular risk factors among apparently health adult Nigerian population-a cross sectional study. BMC Res Notes 2010;3:11.

[38] WHO. Survey of the STEPwise approach for the survellaince of risk factors for non-communicable diseases, Brazzaville, WHO, Region office for Africa, 2007.

[39] Ukoh VA. Admission of hypertensive patients at University of Benin Teaching Hospital, Nigeria. East Afr Med J 2007; 84: 329-335.

[40] Ekore RI, Ajayi IO, Arije A. Case finding for hypertension in young adult patients attending a missionary hospital in Nigeria. Afr Health Sci 2009; 9: 193-199.

[41] Macedo M, Espiga M, Lima MJ, Silva AO, Alcantra P, Ramalhinho V et al. Blood pressure in Portugal: Distribution, Awareness, Treatment and control of hypertension. PAR Study. J Hypertens 2004; XXII(Suppl 1). S 166.

[42] Iloh GUP, Ofoedu JN, Njoku PU, Okafor GOC, Amadi AN, Godswill-Uko EU. Satisfaction with quality of care received by patients without National Health Insurance attending a primary care clinic in a resource-poor environment of a tertiary hospital in Eastern Nigeria in the era of scaling up the Nigerian formal sector health insurance scheme. Annals of Medical and Health Science Research 2013; 3: 31-37.

[43] Iloh GUP, Njoku PU, Ofoedu JN, , Amadi AN, GodswillUko EU. Satisfaction with quality of care: a comparative study of National Health Insurance Scheme and nonNational Health Insurance Scheme patients of a tertiary hospital in South-eastern Nigeria. Port Harcourt Med J 2012; 6: $440-449$.

[44] Timpson NI, Harbord R, DaveySmith G, Zacho J, TybjaergHansen A, Nordestgaard BG. Does greater adiposity increase blood pressure and hypertension risk? Mendelian randomization using FTO/MC4R genotype. Hypertension 2009; 54: 84-90. 
[45] Wallace C, Xue MZ, Caulfield M. Genome scans in hypertension. In Dominiczak AF, Connell JMC, editors. Handbook of Hypertension. Genetics of hypertension. Edinburgh, Elservier 2007; 24, p.49-66.

[46] Inem AV, Ayankogbe OO, Obazee M, Ladipo MM, Udonwa NE, Odusote K. Conceptual and contextual paradigm of the family as a unit of care. Niger Med Pract 2004; 45: 9-13.

[47] Oleribe EOO, Alasia DD. Socio-demographic variables and family health: A prospective study of a Katcha in Northcentral Nigeria. Niger J Med 2006; 15: 427-429.
[48] Rozanski A, Blumenthal JA, Kaplan J. Impact of psychological factors on the pathogenesis of cardiovascular disease and implications for therapy. Circulation 1999; 99: 2192-2217.

[49] Gabor Simmonyi. Chronic stress in the development of essential hypertension, role of rilmendine in the treatment of stress induced hypertension. American Journal of Internal Medicine 2014; 2: 1-5. 